\title{
Peculiarities of Dental Treatment among Paediatric Oncological Patients: a Case Report
}

\author{
Egle Aida Bendoraitiene', Vilija Andruskeviciene', Gabriele Kscenaviciute ${ }^{1}$, Evelina Srebaliene', \\ Ieva Maciulaityte ${ }^{2}$
}

${ }^{1}$ Department of Preventive and Paediatric Dentistry, Lithuanian University of Health Sciences, Kaunas, Lithuania. ${ }^{2}$ Private practice.

\section{Corresponding Author:}

Vilija Andruskeviciene

Sodu 6, LT-53417, Kaunas

Lithuania

Phone: +37068685399

E-mail: vilija.andruskeviciene@1smuni.1t

\begin{abstract}
Objectives: According to the National Cancer Institute of Lithuania, cancer is diagnosed for almost 100 children each year. Oncological patients suffer from complications during and after treatment. Radiation therapy also affects dental hard tissues. Many oncological patients lose motivation to take care of their oral hygiene because they are focused on cancer diagnosis. This case report discusses prevention and dental treatment severity after radiation therapy treatment.

Material and Methods: A 9-year-old boy with cancer diagnosis visited a dentist in 2017. The patient was complaining about poor aesthetic quality of the teeth, but there were no complaints about teeth sensitivity or pain. Different stages of active caries, poor oral hygiene, visible abundant plaque, swollen, red and bleeding gums were observed during appointment. A motivational interview explaining the importance of oral hygiene was conducted. Non-surgical caries treatment was prescribed during the first visit. Restorative treatment was performed after 1 month.

Results: The motivational interview explaining the importance of oral hygiene was conducted during every appointment per 3-year period. Unfortunately, oral hygiene is still poor due to the lack of motivation. Active-cavitated caries lesions were restored with glass ionomer cement and composite resin. The aesthetics of teeth was improved.

Conclusions: Oncological and recovered patients after radiation therapy should be assigned to a high risk of caries. These patients should be treated individually by the algorithm. Psychological or psychotherapeutic assistance is necessary for patients due to motivation for treatment and oral care.
\end{abstract}

Keywords: cancer of head and neck; dental atraumatic restorative treatment; dental caries; pediatric dentistry; radiation; radiotherapy.

\footnotetext{
Accepted for publication: 10 September 2020

To cite this article:

Bendoraitiene EA, Andruskeviciene V, Kscenaviciute G, Srebaliene E, Maciulaityte I.

Peculiarities of Dental Treatment among Paediatric Oncological Patients: a Case Report

J Oral Maxillofac Res 2020;11(3):e5

URL: http://www.ejomr.org/JOMR/archives/2020/3/e5/v11n3e5.pdf

doi: $\underline{10.5037 / \text { jomr.2020.11305 }}$
} 


\section{INTRODUCTION}

Oncological cases in Lithuania are increasing every year. According to the National Cancer Institute (NCI), the rate of oncological patients expands up to $1 \%$ each year. According to NCI, leukaemia (47\%) and malignant brain tumours $(17 \%)$ are the most frequent diagnoses in the age group of $0-14$ years [1]. Head and neck cancer can be treated by a complex of radiotherapy and surgery. Radiationinduced changes can be divided into 2 groups: early or acute side effects that are noted during or shortly after treatment, affecting mucosa, taste and salivary glands; and late side effects that develop months or years after the end of radiation therapy, affecting salivary glands, teeth, bone, muscles and skin [2].

Mucositis, hyposalivation, dysaesthesia, bacterial and fungal infections, osteoradionecrosis and trismus are the most common complications of direct irradiation in patients suffering from head and neck cancer [ $\underline{3}]$. It is known that saliva plays a key role in maintaining oral health because of its clearance mechanisms of food and acids from the mouth. Patients with decreased salivary secretion are more prone to caries than others with normal salivary flow, because of poor bicarbonate buffering of $\mathrm{pH}$ and reduced oral clearance [4].

Radiation therapy (RT) also affects the dental hard tissues increasing their susceptibility to demineralisation [5]. Unfortunately, radiation carries has a rapid onset and quick progress. This is due to the reduced secretion of saliva and, consequently, much impaired self-cleaning of the teeth [ $\underline{3}]$.

The incidence and severity of radiation-induced changes within teeth vary individually, depending on patient's age, actual radiation dose, size of radiation exposure field (position and actual size of the tumour), patient's general condition and additional risk factors (alcoholism, smoking, malnutrition) []].

Prevention of tooth decay can be achieved by initiating pre-radiotherapy dental treatment, frequent dental check-ups, treatment after radiotherapy and regular dental care at home (including the use of fluorides). Unfortunately, restorative dental treatment can be quite difficult after radiotherapy. Dentists should estimate damaged dental tissues and select appropriate filling materials [5]. Many oncological patients lose motivation to take care of their oral hygiene because they are focused on cancer diagnosis. Therefore, after radiotherapy treatment, it is essential to further motivate the patient to maintain adequate oral hygiene. Regular visits should be conducted every three months, as those are aimed at professional prophylaxis, symptomatic treatment of any ailments, as well as the detection and treatment of any new cavities [ $\underline{3}]$.

\section{CASE DESCRIPTION AND RESULTS}

Before child's treatment procedure, we get a consent form signed by the mother and/or father (legal guardian) regarding the treatment plan, participation in the training process and the use of anonymous patient data related to the medical history. Permission form is approved by Ministry of Health.

A 9-year-old boy visited healthcare professionals in October 2015. The patient felt nausea, vomiting and headache episodes, which had been lasting for approximately 2 years. These complaints were investigated and no pathology was found. After 1 month, neck-muscle rigidity manifested for the first time and the patient referred to the hospital. During the appointment, a blood test was taken for suspected borreliosis and tick-borne encephalitis. As a result, borreliosis was diagnosed and etiological treatment was prescribed amoxicillin $500 \mathrm{mg}$ (Sandoz $\mathrm{GmbH}$; Kundl, Austria) taken 3 times daily. Despite the treatment, signs and symptoms still persisted. The computed tomography scan was performed in January 2016 and the brain tumour was diagnosed. After 1 month, tumour resection and ventriculoperitoneal shunt were performed. Hydrocortisone was prescribed before surgical treatment. The patient developed diabetes insipidus symptoms after surgery. The pathohistological diagnosis of the resected tumour was a germinoma. Radiotherapy was applied for 5 weeks. In total, 25 radiotherapy fractions were given. In November 2017, after a preventive dental checkup, the patient was referred from a primary healthcare centre to the Department of Preventive and Paediatric Dentistry, Hospital of Lithuanian University of Health Sciences Kauno Klinikos (LSMUL KK). The general dentist's diagnosis was multiple active caries lesions and oncological anamnesis.

\section{First visit \\ Anamnesis}

The patient was complaining about poor aesthetic quality of the teeth, but there were no complaints about teeth sensitivity or pain. The oncological anamnesis was cleared up. The patient's father mentioned that during radiological treatment his child's appetite was bad and the main source of food was sweets. Besides, the main focus was on the oncological disease. Thus, oral hygiene, principles of 
food and nutrition were not important at that time.

The patient was asked about his eating habits and it turned out that he had been consuming a lot of snacks and carbonated beverages at school. Oral hygiene habits were also investigated, which showed that the patient did not brush his teeth daily, parents did not know about the amount of fluoride in his toothpaste, and no additional oral hygiene products were used.

\section{Oral examination}

Different stages of active caries, poor oral hygiene, visible abundant plaque, swollen, red and bleeding gums were observed. The patient was diagnosed with multiple active dental caries and chronic gingivitis, which is in a group of a high risk for dental caries (Figure 1).

\section{Procedure technique}

The plaque was dyed with GC Tri Plaque ID Gel ${ }^{\mathrm{TM}}$ (GC Corporation; Tokyo, Japan), and the index of oral hygiene level (OHI-S) index 3 was determined (Figure 2). A motivational interview explaining the importance of oral hygiene was conducted along with instructions about correct dental cleaning. Nonsurgical caries treatment was prescribed: GC MI Paste Plus $^{\circledR}$ (GC Corporation; Tokyo, Japan), Elgydium ${ }^{\circledR}$ Junior toothpaste (Pierre Fabre; Paris, France) for children aged $7-12$, which contained 1350 ppm F, a soft toothbrush for cleaning teeth and an additional single toothbrush. In addition, the use of interdental thread was recommended.

The next visit for the evaluation of the patient's oral hygiene was scheduled after 4 weeks.

\section{Second visit}

In December 2017, the patient came to the Department of Preventive and Paediatric Dentistry, LSMUL KK.

\section{Anamnesis}

The patient did not feel pain. He claimed that he had been brushing teeth 2 times a day, using the recommended measures. He claimed that he had reduced sweet snacks and carbonated drinks.

\section{Oral examination}

Oral examination showed better oral hygiene, reduced visible plaque and slight redness of the gums.

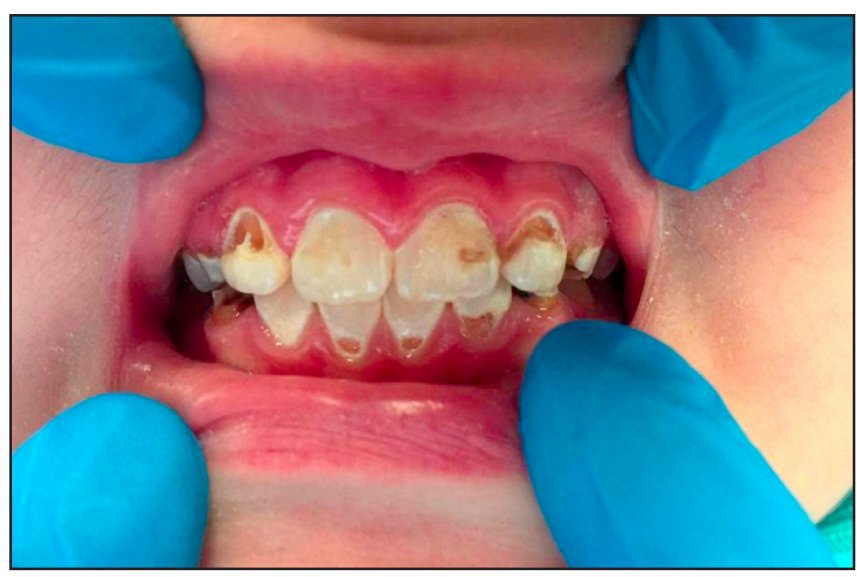

Figure 1. The condition of patient's anterior teeth during the first visit.

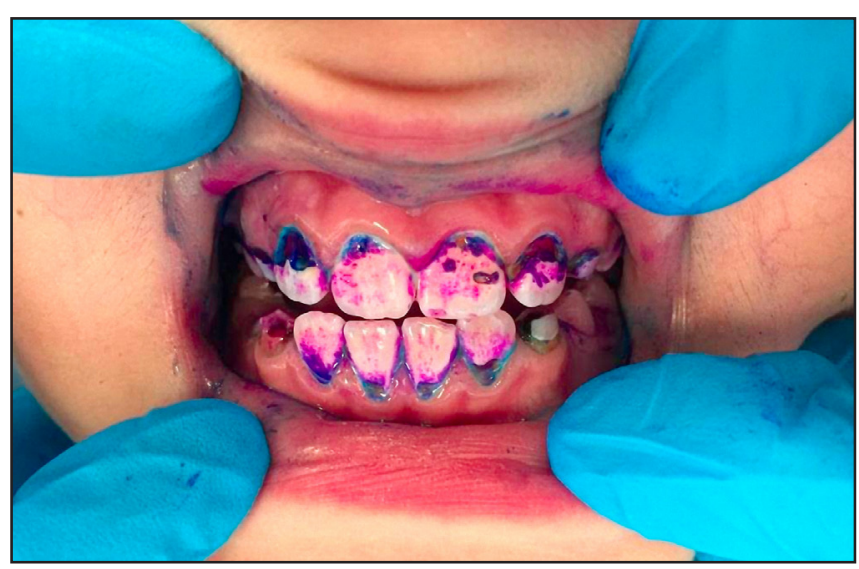

Figure 2. After dying with the GC Tri Plaque ID Gel ${ }^{\mathrm{TM}}$.

\section{Procedure technique}

The plaque was dyed with GC Tri Plaque ID Gel ${ }^{\mathrm{TM}}$, and the OHI-S index 2 was determined. Better oral hygiene allowed preparation of teeth 11, 12, 21, 22, 31,32 , and 41 by a minimally invasive method, using a dental excavator to remove soft dentin. Enamel crusts were removed by a ball sphere diamond burr. The teeth were restored with GC Fuji IX GP ${ }^{\circledR}$ (GC Corporation; Tokyo, Japan) and then polished (Figure 3). The patient was repeatedly instructed about correct dental cleaning.

The patient was referred to his regional clinic for further control.

\section{Third visit}

In November 2018, the patient came to the Department of Preventive and Paediatric Dentistry, LSMUL KK.

\section{Anamnesis}

The patient complained about two teeth restorations 


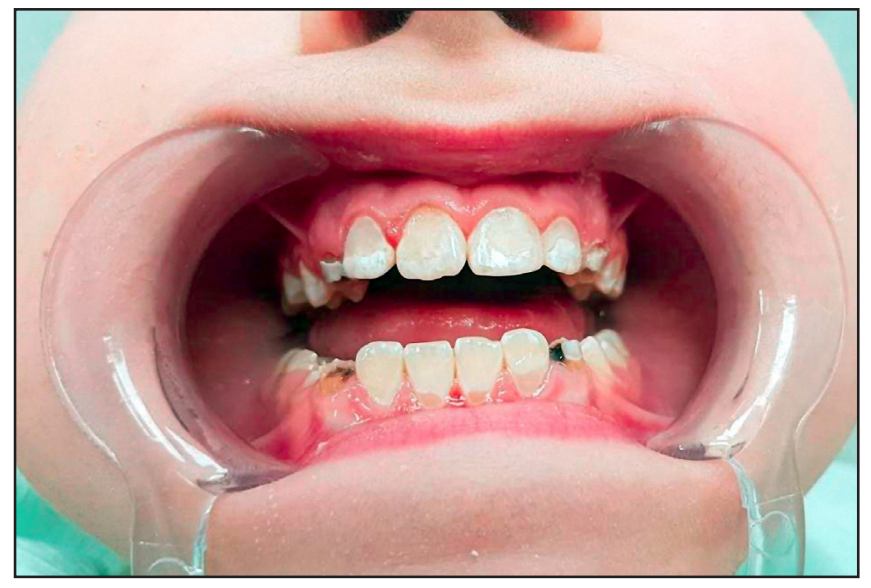

Figure 3. Teeth after restorations.

that had fallen out, but he did not mention any pain (Figure 4). The patient claimed that he had been brushing teeth 2 times a day, but he could not specify the toothpaste he had been using. The patient did not take any other oral hygiene measures. His diet was irregular.

\section{Oral examination}

It was observed that restorations of teeth 11 and 12 had fallen out while restorations of teeth $21,22,32$, 31,41 and 42 teeth had been damaged. However, caries stabilised in the areas where glass ionomer cement (GIC) was applied. Soft plaque was visible on all teeth. The gums were slightly red, swollen and bleeding.

\section{Procedure technique}

The plaque was dyed with GC Tri Plaque ID Gel ${ }^{\mathrm{TM}}$, and the OHI-S index 3 was determined. Furthermore, the teeth were cleaned with a toothbrush (Kerr, OptiShine ${ }^{\mathrm{TM}}$ - KerrHawe SA, Bioggio, Switzerland) and polished using polishing paste (3M ESPE Clinpro Prophy Paste - 3M Corporate Headquarters, Saint Paul USA). A motivational interview was conducted. Besides, tablets for plaque control were prescribed for use at home.

\section{Fourth visit}

In January, 2019, the patient came for examination

\section{Procedure technique}

The teeth were cleaned with a toothbrush drill (Kerr, OptiShine ${ }^{\mathrm{TM}}$ - KerrHawe SA, Bioggio, Switzerland) using toothpaste (3M ESPE Clinpro Prophy Paste - 3M Corporate Headquarters, Saint Paul, USA).

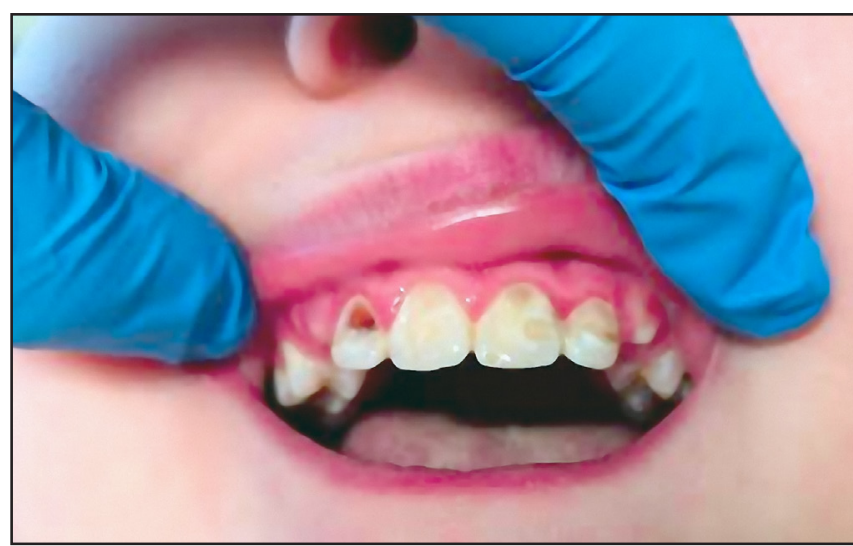

Figure 4. Arrested caries after restorations using glass ionomer cement.

Teeth 12,11, 21, 22, 32, 31, 41 and 42 teeth were restored using light curing composite Enamel Plus HRI Flow UD2 and UD3 syringes (MICERIUM S.p.A.; Avegno, Italy).

\section{Fifth visit}

In May 2019, the patient came for examination.

\section{Anamnesis}

The patient did not have any complaints. He had been brushing his teeth irregularly using the Elgydium ${ }^{\circledR}$ Junior toothpaste containing $1350 \mathrm{ppm} \mathrm{F}$. The patient's diet mostly contained easily degradable carbohydrates and frequently consumed snacks.

\section{Oral examination}

Plaque was visible on all teeth. The gums were swollen, slightly red and bleeding. The teeth restorations were in good quality.

\section{Procedure technique}

The plaque was dyed with GC Tri Plaque ID Gel ${ }^{\mathrm{TM}}$, and the OHI-S index 3 was determined. The teeth were cleaned with a toothbrush drill (Kerr, OptiShine $^{\mathrm{TM}}$ - KerrHawe SA, Bioggio, Switzerland) using toothpaste (3M ESPE Clinpro Prophy Paste - 3M Corporate Headquarters, Saint Paul USA). A motivational interview was conducted explaining the importance of oral hygiene along with instructions of correct dental cleaning. Previously prescribed oral care measures were recommended.

\section{Sixth visit}

In October 2019, the patient came for another visit. 


\section{Anamnesis}

The patient did not have any complaints. He claimed that he had been brushing his teeth 2 times a day using toothpaste (Elgydium ${ }^{\circledR}$ Junior toothpaste (Pierre Fabre; Paris, France) which contained 1350 ppm F. The patient's diet was still irregular.

\section{Oral examination}

The teeth restorations were in good quality; however, there was plaque on the precervical area of the crown. Marginal edge gingivitis was indicated (Figure 5).

\section{Procedure technique}

The teeth were cleaned with a toothbrush drill (Kerr, OptiShine $^{\mathrm{TM}}$ - KerrHawe SA, Bioggio, Switzerland) using toothpaste (3M ESPE Clinpro Prophy Paste - 3M Corporate Headquarters, Saint Paul USA). A motivational interview was conducted along with an explanation of the importance of a healthy diet.

\section{DISCUSSION}

Post-radiation caries is a rapidly progressing and highly destructive type of dental caries. Radiation caries usually sets in on the smooth, occlusal surface of the incisors, premolars and molars. Therefore, radiation caries can damage the area around the neck of the teeth, and typically affects more than one surface. Radiation-related caries and other dental hard tissue changes can appear within the first 3 months following RT, but the most affected changes are observed after 1 year $[\underline{3}, \underline{5}]$. In our case, the patient applied to the dentist after 18 months post radiotherapy. Active (cavitated and non-cavitated) caries lesions were detected during the appointment.

The main measure to stabilise the condition is the elimination of etiological factors. Radiation caries is not primarily caused by the effect of radiotherapy; however, it can still influence the development of caries. The main etiological factor in the development of caries is the dental biofilm [3]. In our case, we think that the patient and his parents were not motivated to follow the dentist's instructions of oral hygiene. The OHI-S did not improve enough during the treatment. Even though conversations about motivation, oral hygiene instructions and oral care product recommendations were conducted by the dentist during every appointment, the results were poor. Besides, chronic gingivitis was diagnosed during the first visit due to inadequate oral hygiene and it did

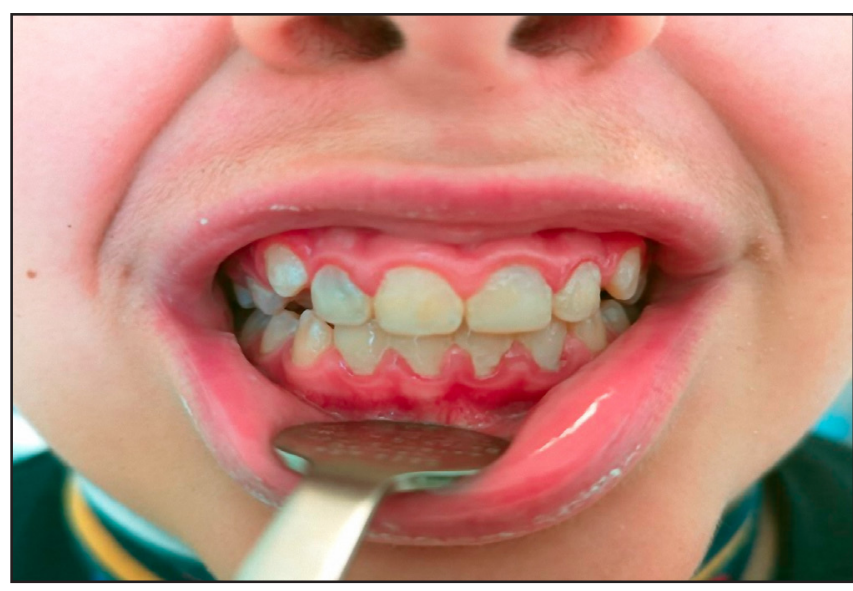

Figure 5. Patient's oral hygiene condition.

not show signs of improvement during other visits. We can assume that gingivitis might be influenced by radiological treatment. Scientific literature states that xerostomia is a frequent complication of RT treatment that results in increased accumulation of biofilm [6] In such cases, good and responsible control of oral hygiene is required. Perhaps the lack of patient's motivation can be explained by the fact that cancer treatment did not only cause various complications, but also affected the family's psychosocial life [7]. After cancer diagnosis, families can experience difficulties due to uncertainty about the future, the disappearance of normal family life and financial problems [8]. During the treatment process, children are often concerned about their illness, they feel sad and isolated. Children and adolescents can feel challenged, experience deterioration in body image, loss of independence, peer bullying, and ridicule. Treatment for children with cancer has usually been focused on physical interventions, whereas psychosocial interventions have remained limited $[\underline{7}, \underline{8}]$.

When analysing the risk factors for oral diseases, it is necessary to mention a patient's habit of eating sweets and drinking sweet, carbonated drinks. The literature states that teenager and young adult cancer patients or survivors have low levels of physical activity, consume relatively poor diets, often struggle with weight gain, and engage in health-risk behaviours such as smoking and alcohol consumption. They do not meet recommendations for fibre, fat or sugar intake [9]. It is known that the frequency of carbohydrate intake can be related to the development of caries [10]. Recent literature discusses an integrated hypothesis of caries and periodontal diseases and aims to find the interface between sugar consumption and periodontal diseases [4]. It is important to mention that sugar intake may be associated with obesity and systemic 
inflammation [11]. Sugar consumption can affect the main disease. It is recommended to use a fat-rich, low-carbohydrate diet during cancer therapy. It may help to reduce circulating glucose levels and induce ketosis so that cancer cells starve while normal cells adapt their metabolism to use ketone bodies and survive. Furthermore, by reducing blood glucose levels, the amount of insulin and insulin-like growth factor in blood decreases, which are important drivers of cancer cell proliferation [12].

It seems that in cases such as ours, conventional ways of changing patient behaviour and motivation may not be enough to ensure good oral hygiene and a healthy diet. In our opinion, one effective solution could be participation in special programmes where parents and children with chronic illnesses (such as cancer, asthma or diabetes) are provided with support resources for coping with psychological problems. These programmes include coping skills, cognitive behavioural approaches involving relaxation exercises, group-based therapeutic exercise programmes, yoga, guided imagery, hypnotic relaxation, meditation and physical exercise. As a result, it has been determined that children who participated in such programmes show a decrease in anxiety levels and improvement of their sleep quality. Their quality of life, self-efficacy, and coping skills improve $[\underline{8}, \underline{13}, \underline{14}]$.

Choosing the right restoration material for patients with oncological diseases often becomes a real challenge for the dentist. In our case, the defects were initially sealed with GIC due to active caries and soft dentin. Softened dentin was only removed using an excavator, while demineralised enamel edges were eliminated with a drill. Unfortunately, filling adherence was not good due to poor integration of the marginal edge. For this reason, some of the restorations fell out. However, GIC also provided some benefits. It completely stabilised the lesion at certain locations, which allowed filling the defects with composite materials during the next appointment. This healing tactic has been confirmed by other authors, who claim that GIC causes caries inhibition, but leads to easy disintegration, especially in pre-cervical areas of the teeth [15]. Meanwhile, composites have greater structural integrity compared with GIC. It is believed that GIC provides better protection against the development of secondary caries compared with composite resins in patients with oncological diseases. In addition, it is recommended to use a 'sandwich' sealing technique (first layer of GIC, second layer of composite resin), but 2 years should pass after RT and oral health should be appropriate $[\underline{15}, \underline{16}]$. There is no ideal material for filling defects, but the dentist should take into account the patient's oral hygiene, motivation and comorbidities $[\underline{15}, \underline{17}]$.

The oral condition of our patient is being monitored. It is observed that the adhesion of seals is good, there is no penetrability, but the management of oral hygiene still remains poor.

\section{CONCLUSIONS}

To sum up, oncological and recovered patients after radiation therapy should be assigned to a high risk of caries. These patients should be treated individually by the algorithm. After finishing oncological treatment, some risk factors of caries may disappear. However, there is a possibility that some habits such as poor oral hygiene and a caries-friendly diet could still remain after the treatment. Additionally, the psychological and psychotherapeutic assistance should be included along with the methods normally used by dentists during the treatment in order to shape new adequate habits.

\section{ACKNOWLEDGMENTS AND DISCLOSURE STATEMENTS}

The authors report no conflicts of interest related to this study.

\section{REFERENCES}

1. National Cancer Institute, Control and Prevention Center. Cancer Registry. [Vèžys Lietuvoje 2012 metais]. Vilnius; 2015. [URL: https://www.nvi.lt/uploads/pdf/Vezio\%20registras/Vezys lietuvoje 2012.pdf]

2. Otmani N. Oral and maxillofacial side effects of radiation therapy on children. J Can Dent Assoc. 2007 Apr;73(3):257-61. [Medline: 17439713]

3. Dobroś K, Hajto-Bryk J, Wróblewska M, Zarzecka J. Radiation-induced caries as the late effect of radiation therapy in the head and neck region. Contemp Oncol (Pozn). 2016;20(4):287-90. [Medline: 27688724] [PMC free article: 5032152] [doi: 10.5114/wo.2015.54081]

4. Nyvad B, Takahashi N. Integrated hypothesis of dental caries and periodontal diseases. J Oral Microbiol. 2020 Jan 7;12(1):1710953. [Medline: 32002131] [PMC free article: 6968559] [doi: 10.1080/20002297.2019.1710953] 
5. Gupta N, Pal M, Rawat S, Grewal MS, Garg H, Chauhan D, Ahlawat P, Tandon S, Khurana R, Pahuja AK, Mayank M, Devnani B. Radiation-induced dental caries, prevention and treatment - A systematic review. Natl J Maxillofac Surg. 2015 Jul-Dec;6(2):160-6. [Medline: 27390489] [PMC free article: 4922225] [doi: 10.4103/0975-5950.183870]

6. Ammajan RR, Joseph R, Rajeev R, Choudhary K, Vidhyadharan K. Assessment of periodontal changes in patients undergoing radiotherapy for head and neck malignancy: a hospital-based study. J Cancer Res Ther. 2013 Oct-Dec;9(4):630-7. [Medline: 24518708] [doi: 10.4103/0973-1482.126461]

7. Patterson JM, Holm KE, Gurney JG. The impact of childhood cancer on the family: a qualitative analysis of strains, resources, and coping behaviors. Psychooncology. 2004 Jun;13(6):390-407. [Medline: 15188446] [doi: 10.1002/pon.761]

8. Sengul ZK, Toruner EK. Intervention Protocol: Technology-Based Psychosocial Motivation for Children with Cancer and Their Parents: A Randomized Trial. Asia Pac J Oncol Nurs. 2019 Jun 24;7(1):55-63. [Medline: 31879685] [PMC free article: 6927163] [doi: 10.4103/apjon.apjon 25 19]

9. Pugh G, Hough R, Gravestock H, Fisher A. The health behaviour status of teenage and young adult cancer patients and survivors in the United Kingdom. Support Care Cancer. 2020 Feb;28(2):767-777. [Medline: 31144171] [PMC free article: 6954124] [doi: 10.1007/s00520-019-04719-y]

10. Rugg-Gunn A. Dental caries: strategies to control this preventable disease. Acta Med Acad. 2013 Nov;42(2):117-30. [Medline: 24308392] [doi: 10.5644/ama2006-124.80]

11. Carmo CDS, Ribeiro MRC, Teixeira JXP, Alves CMC, Franco MM, França AKTC, Benatti BB, Cunha-Cruz J, Ribeiro CCC. Added Sugar Consumption and Chronic Oral Disease Burden among Adolescents in Brazil. J Dent Res. 2018 May;97(5):508-514. [Medline: 29342369] [doi: 10.1177/0022034517745326]

12. Weber DD, Aminazdeh-Gohari S, Kofler B. Ketogenic diet in cancer therapy. Aging (Albany NY). 2018 Feb 11;10(2):164165. [Medline: 29443693] [PMC free article: 5842847] [doi: 10.18632/aging.101382]

13. van Dijk-Lokkart EM, Braam KI, Kaspers GJ, van Dulmen-den Broeder E, Takken T, Grootenhuis MA, Streng IC, Bierings M, Merks JH, van den Heuvel-Eibrink MM, Veening MA, Huisman J. Applicability and evaluation of a psychosocial intervention program for childhood cancer patients. Support Care Cancer. 2015 Aug;23(8):2327-33. [Medline: 25577501] [doi: 10.1007/s00520-014-2576-6]

14. van Dijk-Lokkart EM, Braam KI, van Dulmen-den Broeder E, Kaspers GJ, Takken T, Grootenhuis MA, Streng IC, Bierings M, Merks JH, van den Heuvel-Eibrink MM, Veening MA, Huisman J. Effects of a combined physical and psychosocial intervention program for childhood cancer patients on quality of life and psychosocial functioning: results of the QLIM randomized clinical trial. Psychooncology. 2016 Jul;25(7):815-22. [Medline: 26509236] [doi: $10.1002 /$ pon.4016]

15. De Moor RJ, Stassen IG, van 't Veldt Y, Torbeyns D, Hommez GM. Two-year clinical performance of glass ionomer and resin composite restorations in xerostomic head- and neck-irradiated cancer patients. Clin Oral Investig. 2011 Feb;15(1):31-8. [Medline: 19997859] [doi: 10.1007/s00784-009-0355-4]

16. Sennhenn-Kirchner S, Freund F, Grundmann S, Martin A, Borg-von Zepelin M, Christiansen H, Wolff HA, Jacobs HG. Dental therapy before and after radiotherapy--an evaluation on patients with head and neck malignancies. Clin Oral Investig. 2009 Jun;13(2):157-64. [Medline: 18925418] [PMC free article: 3085778] [doi: 10.1007/s00784-008-0229-1]

17. McComb D, Erickson RL, Maxymiw WG, Wood RE. A clinical comparison of glass ionomer, resin-modified glass ionomer and resin composite restorations in the treatment of cervical caries in xerostomic head and neck radiation patients. Oper Dent. 2002 Sep-Oct;27(5):430-7. [Medline: 12216559]

\section{To cite this article:}

Bendoraitiene EA, Andruskeviciene V, Kscenaviciute G, Srebaliene E, Maciulaityte I.

Peculiarities of Dental Treatment among Paediatric Oncological Patients: a Case Report

J Oral Maxillofac Res 2020;11(3):e5

URL: http://www.ejomr.org/JOMR/archives/2020/3/e5/v11n3e5.pdf

doi: $10.5037 /$ jomr.2020.11305

Copyright (C) Bendoraitiene EA, Andruskeviciene V, Kscenaviciute G, Srebaliene E, Maciulaityte I. Published in the JOURNAL OF ORAL \& MAXILLOFACIAL RESEARCH (http://www.ejomr.org), 30 September 2020.

This is an open-access article, first published in the JOURNAL OF ORAL \& MAXILLOFACIAL RESEARCH, distributed under the terms of the Creative Commons Attribution-Noncommercial-No Derivative Works 3.0 Unported License, which permits unrestricted non-commercial use, distribution, and reproduction in any medium, provided the original work and is properly cited. The copyright, license information and link to the original publication on (http://www.ejomr.org) must be included. 